\title{
Erratum
}

Strahlenther Onkol 2013 · 189:1060-1060

DOI 10.1007/s00066-013-0499-7

P. Farace , M.A. Deidda, I. lamundo de Cumis, E. Deiana, R. Farigu, G. Lay and S. Porru

Department of Radio-Oncology, Regional Oncological Hospital, via Jenner, 09121 Cagliari, Italy

\section{Erratum to: Bi-tangential hybrid IMRT for sparing the shoulder in whole breast irradiation}

The authors and the publishing editor regret a typing error in the list of authors in Strahlentherapie und Onkologie 189:967-971.

The correction in the list of authors is shown in italics:

P. Farace, M.A. Deidda, I. Iamundo de Cumis, E. Deiana, R. Farigu, G. Lay and S. Porru

\section{Corresponding address}

P. Farace

Department of Radio-Oncology, Regional

Oncological Hospital,

via Jenner, 09121 Cagliari

Italy

paolofarace@gmail.com 